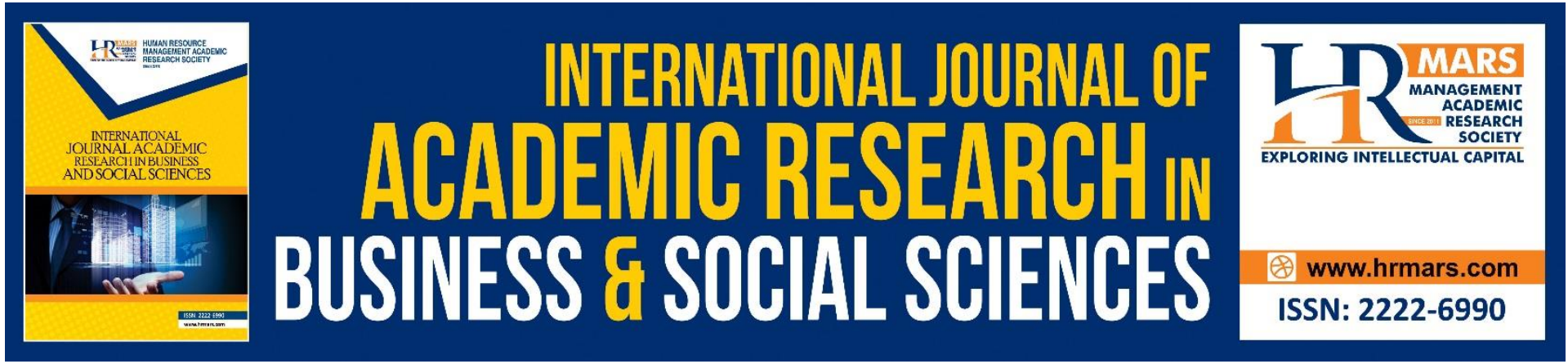

\title{
Household Food Waste: Exploring the Modern Throw-away Culture in Raub, Pahang, Malaysia
}

Siti Hasziani Ahmad, Fazreena Mansor, Noor Junaini Arwin Yaacob, Nurul Izzat Kamaruddin, Roslina Ali

To Link this Article: http://dx.doi.org/10.6007/IJARBSS/v11-i7/10397 DOI:10.6007/IJARBSS/v11-i7/10397

Received: 20 May 2021, Revised: 22 June 2021, Accepted: 15 July 2021

Published Online: 28 July 2021

In-Text Citation: (Ahmad et al., 2021)

To Cite this Article: Ahmad, S. H., Mansor, F., Yaacob, N. J. A., Kamaruddin, N. I., \& Ali, R. (2021). Household Food Waste: Exploring the Modern Throw-away Culture in Raub, Pahang, Malaysia. International Journal of Academic Research in Business and Social Sciences, 11(5), 1508-1524.

Copyright: (c) 2021 The Author(s)

Published by Human Resource Management Academic Research Society (www.hrmars.com)

This article is published under the Creative Commons Attribution (CC BY 4.0) license. Anyone may reproduce, distribute, translate and create derivative works of this article (for both commercial and non-commercial purposes), subject to full attribution to the original publication and authors. The full terms of this license may be seen

at: http://creativecommons.org/licences/by/4.0/legalcode

Vol. 11, No. 7, 2021, Pg. 1508 - 1524

http://hrmars.com/index.php/pages/detail/IJARBSS

JOURNAL HOMEPAGE

Full Terms \& Conditions of access and use can be found at http://hrmars.com/index.php/pages/detail/publication-ethics 


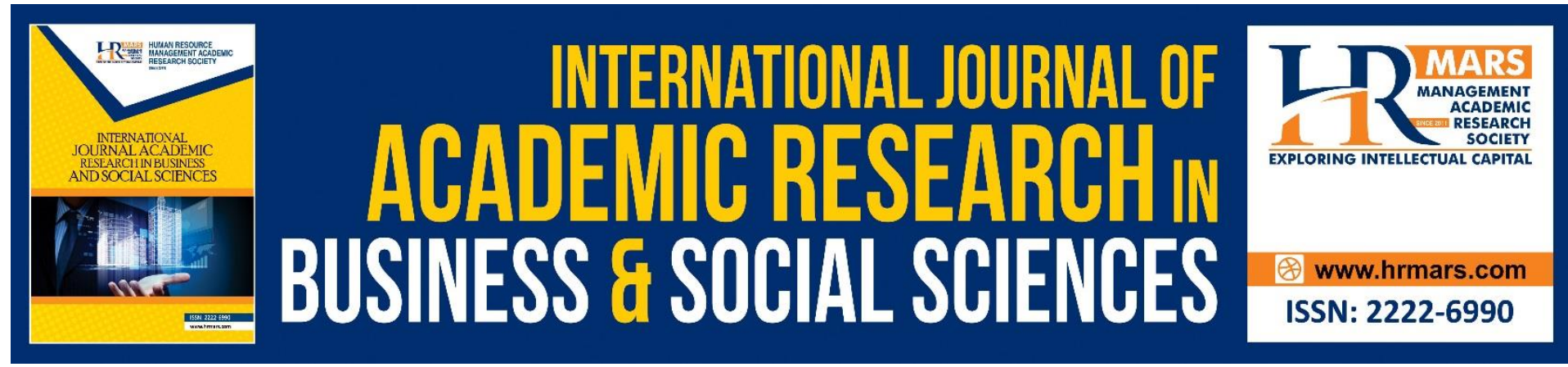

\title{
Household Food Waste: Exploring the Modern Throw-away Culture in Raub, Pahang, Malaysia
}

\author{
Siti Hasziani Ahmad, Fazreena Mansor, Noor Junaini Arwin \\ Yaacob, Nurul Izzat Kamaruddin, Roslina Ali \\ Faculty of Business \& Management, Universiti Teknologi MARA Pahang, Raub Campus
}

\begin{abstract}
Food waste has formidable harmful consequences for food security, the environment, the economy, and biodiversity loss, making it a worldwide issue that demands immediate action. Reducing the amount of food waste has been deemed critical in Malaysia, thus, this study investigates the factors related to household food wastage with the aims of identifying the level of awareness as well as the causes and effects of food waste among residents of Raub, Pahang. It presents a qualitative research approach to allow the researcher to explore deeper into the area of minimizing household food waste. The findings suggest that the level of awareness and understanding of the impact of food waste on the environment among the households in Raub, Pahang, Malaysia is still low. As the food waste issue is positioned as an "end of pipe", further initiatives involving more people in the whole food system should be considered as well as awareness since everyone holds the responsibility to reduce waste.
\end{abstract}

Keyword: Food Waste, Awareness, Implication, Effect, Factor

\section{Introduction}

Food waste either cooked or leftovers are becoming a major problem around the world due to the growing world population. The exponential growth in food waste is striking as a serious threat to our society, such as environmental pollution, health risk and scarcity of dumpling land (Paritosh et al., 2017). As reported by the United Nations Environment Programme (UNEP) and the World Resources Institute (WRI), one-third of all food produced worldwide is wasted or lost on annual basis and households contribute half of the food wasted (Jorissen et al., 2015).

Schanes et al (2018) stated that consumer behaviour or environmental psychology as the reason behind wasted food at the household's level. Through this approach, it revealed the casual relationships between perceptive as well as socio-demographic variables and actions for instance individual's behaviours, norms, knowledge and intentions.

In 2020, people are forced to stay at home by the implementation of Malaysia Movement Control Order (MCO) because of Coronavirus (COVID-19) outbreak. It a drastic change in lifestyle and most of the people are urged to stay at home and to go out only for the 
necessities and emergency. Consequently, COVID-19 had caused a drop in household consumption and a shift in their life also spending habits (Jribi et al., 2020).

According to Elimelech et al (2018), household food waste reported for $45 \%$ of total waste which is equivalent to $573 \mathrm{~g}$ per day per capita of which $54 \%$ was identified as preventable. Roughly, two-thirds of preventable waste consisted of vegetables and fruit. There are around 3000 tonnes out of 15,000 tonnes of wasted food in Malaysia that are actually edible and it should not be wasted. During festive seasons, the quantity of wasted food is increasing by 15\% to 20\% (Solid Waste Management Report (2015). Based on Khazanah Research Institute (KRI), 44.5\% of the total solid waste are generated by household sectors, amounting to 6.1 million tonnes a year. Municipal Solid Waste (MSW) is be made up of 20 different categories including food waste, which is made up $50 \%$ of the total waste composition, and household is the main source of MSW (Sundaram et al., 2019).

In fact, in Malaysia, Jereme et al., (2016) in their studies claimed that recycling activities are still significantly uncommon compared to other neighbouring countries such as Singapore. According to Jarjusey \& Chamhuri (2017), people's inadequate awareness about food waste can be the reason for a higher amount of food waste, and the pre-shopping activities could poorly affect the food waste behaviour. Meanwhile, more people in the society are aware of the impact of food waste on the economic. Little did they know that food waste does affect environmental too.

Based on the latest study by Hamilton, Denniss \& Baker (2005), Exodus Market Research (2007); Lyndhurst (2007), they aimed to understand the food waste behaviour of customers that reportedly of high rates of unawareness among customers toward the issue. According to Hamilton et al (2005) $71 \%$ of Australians have confidence that they rarely or at least irregularly purchase products that they end up wasting.

Households also represent the last step of the supply chain and because of that, they are the most important target for food waste reduction initiatives (Schanes et al., 2018). Many attempts have been made to explore the food waste handling, management, challenges, and policies in Malaysia (see example, Papargyropoulou et al., 2014; Lim et al., 2016; Jereme, Siwar, Begum, \& Talib, 2016; Kasavan, Mohamed, \& Halim, 2019; Zainal, \& Hassan, 2019; Ismail et al., 2020), astonishingly, there is no research has been done so far to identify the factors and awareness amongst the households in Raub, Pahang, Malaysia. As stated by Parizeau et al (2015) a suitable involvement to reduce household food waste need placebased and geographically sensitive analyses that take into consideration the specificities of local food and waste management system, also the cultural norms concerning food. Bridging the gap, this study, therefore, provides new empirical data in the less-studied area and field of waste generation, by presenting a case study in Raub, Pahang, Malaysia.

It is believed that communities living in Raub, Pahang, Malaysia supposedly show more appreciation towards food production and maximize food utilization. Evidently, the largest proportion of total food waste arises from households. It is believed that by increasing awareness and knowledge of food waste management among households will be the best initial step, be it for the urban or rural society, to reduce their food waste volume. The objectives of this study, therefore, attempts to analyse: 
- the factors related to the household food wastage

- awareness and knowledge of food waste among the household in Raub

\section{Literature Review}

Food waste concept

Food waste is known as one of the key issues in the environment, society and economic sustainability, for the world either developed or developing countries (Papargyropoulou et al., 2016). Food waste has given rise up to the impact on food security, predominantly in feeding the world's growing population (Priefer and Juliane Jörissen, 2016; Loke and Leung, 2015).

Nearly 1.3 billion tons of foods or equivalent to 1 over 3 of everything produced is wasted every year as showed by The Food and Agriculture (FAO) of the United Nations, either lost during the food supply chain from the main production to last production (Gustavsson, Cenderberg, \& Sonesson, 2011; Porpino, Parente, \& Wansink, 2015).

Food waste is described as food that is fitted to eat but being thrown due to spoilage. In lowerincome countries, wasted food happened during the production phase, whereas in middle and high-income countries, wasted food occurred during the last phase of the household (United State Department of Agriculture, 2019).

According to Chien Bong et al. (2017), normal households in Malaysia are producing around $0.5 \mathrm{~kg}$ to $0.8 \mathrm{~kg}$ of food waste per day. In Malaysia, food waste is disposed on landfill because its knowingly inexpensive and easy to apply (Lim et al., 2016), yet, there are numerous environmental problems occurred such as groundwater pollution, toxic gas emissions, odours and leachate (Karim Ghani et al., 2013). Menna et al (2018) stated, the decomposing of food waste in landfills produces methane, a greenhouse gas, which is 21 times more potent than $\mathrm{CO} 2$ and it leads to climate change. Furthermore, once landfill site has reached the maximum capacity of usage, it is becoming a serious problem in order to identify a suitable location for the new landfills (Mohamed et al., 2017).

In Malaysia, the sources of food waste were resulting from residential, commercial, institutional, commercial and city areas (Ismail et al., 2020). SWCorp (2015) stated, in Malaysia, a household of five allocate an average of RM900 a month on food, and that a quarter of that food is wasted during preparation, cooking and usage. Approximately means that about RM225 is being thrown away into the dustbin every month, which is RM2700 a year per household.

\section{Factors influencing food waste}

Knowledge is one of the important aspects in determining the behaviour of a business organization and influencing decision making (Samdin et al., 2012). This can be supported by Principato et al. (2015) saying that knowledge is about a particular behaviour and its consequences are assumed to be influential on one's attitudes towards the behaviour. For example, knowledge about the environmental consequences of waste has influenced the intention to reduce the waste (Barr, 2007). In relation to the association between knowledge on food waste and food waste behaviour, (Barr, 2007) reported that knowledge on policy 
measures to reduce waste, in general was found to improve waste reduction behaviour, yet on a small scale only. Perhaps, the extent of knowledge gathered on food waste and its consequences, as well as the degree to which the knowledge is translated into practices, may influence the extent of food waste behaviour. Lack of knowledge is also a significant problem, and even informed consumers have trouble with implementing their knowledge during their everyday activities (Porpino et al. 2016). In addition, creating awareness and understanding of food waste impacts on the environment is one of the effective ways to promote sustainable food waste (Zainal \& Khana, 2019). Kasavan et al (2018) also mention that knowledge regarding reducing food waste should be studied at every stage, from the purchasing of raw food ingredients, food storage, cooking, consumption, to the disposal of food waste. Furthermore, according to an investigation by Mustafa and Yusoff (2011) knowledge alone was not sufficient to motivate an individual to modify his behaviour, but a strong positive attitude would maintain a certain behaviour in the long term.

Household food waste behaviour have been investigated from the perspective of consumer behaviour. Behaviours such as diet importance (Visschers et al., 2016), price orientation (Aschemann-Witzel et al., 2018), planning behaviour (Diaz-Ruiz et al., 2018; Hebrok and Boks, 2017; Stancu et al., 2016), preventive and recycling behaviours as well as environmental awareness (Diaz-Ruiz et al., 2018; Hebrok and Boks, 2017; Stancu et al., 2016) have been considered to influence household food waste generation. While the direct relationship between household food waste generation and consumer behaviour has been widely studied, other factors may impact household food waste behaviours by indirectly influencing consumer behaviour (Hebrok and Boks, 2017; llyuk, 2018). Researchers tend to agree that changing consumer behaviour by raising awareness and putting routine activities in a different light are key factors in enhancing the sustainability of the food chain (Evans, 2011; Wharton et al., 2014; Stancuet al., 2016; Stangherlin and Barcellos, 2018). Lee (2018) found that among several reasons for food waste caused by over purchase at hypermarkets and supermarkets were that participants simply forgot about the food and didn't have the time to eat or cook it. As reported in the above studies, factors such as food access may also influence household waste behaviour as arguably, households tend to purchase more at a less accessible food source. Over-purchase may then lead to food waste as products may expire before consumption.

Household food-related routines may also influence the amount of food waste. Planning routines such as checking inventories or planning meals in advance can contribute to a lower amount of food waste (Stefan et al., 2013; Di et al., 2010), while overcooking may lead to an increased amount of food waste (Griffin et al., 2019). Household food waste prevention begins with the shopping behaviour (Bravi et al., 2018), whereby consumers tend to be influenced by many incentives such as special offers and several psychological traps. Therefore, pre-shop planning and the use of shopping lists represent good practices for minimising food waste. Shopping lists refer to the physical planning of the shopping event and the extent to which the person uses a shopping list in order to have a planned food purchase rather than an impulsive purchase. In addition, planning meals on a regular basis, for example on weekly basis, may assist the households to estimate the food to buy and the amount needed to prepare the meals. This will consequently reduce the probability of food waste. Other than the shopping routines, leftovers routines may also cause a huge amount of food waste. For example, The Electrolux Food Waste Home Survey in the year 2016 reported that young Malaysians are the highest contributors to food waste, whereby on average, they 
threw away slightly two plates of food per week (Jay, 2019). Despite the respondents' passion for cooking, almost all respondents admitted that they throw away leftovers, even after freezing or refrigerating the meals. The survey also highlighted the fact that $70 \%$ of the respondents utilise leftovers, but only practice them once a week. Results from the extant literature documented the influence of households' shopping routines on the amount of food waste thrown away, consistent with the finding of this study. For example, planned shopping activities can mitigate the tendency of overbuying, thus lead to less amount of food thrown away (Bravi et al., 2019, Stefan, et al., 2013, Østergaard, et al., 2018).

\section{Effects of Food Waste}

Food waste is a societal issue with far-reaching effects, including the influence of food waste on global food security, as well as economic and environmental consequences associated with food production and waste (Kibler et al., 2018). According to Rohini et al (2020), food waste means that the valuable and often scarce resources such as water, soil, and energy that were put in the production of that food are lost, and it also worsens climate change. Wastage of food not only has a negative impact on the individuals of the nations but the economy and the environment. Economically, it is a waste of an investment that can reduce the income of a farmer and increase a consumer's expenses. Environmentally, the impact includes excessive emission of greenhouse gases, extensive \& inefficient use of water, and minerals thus diminishing the natural ecosystem in which we live in.

Food production, according to Seberini (2019) is one of the most resource-intensive industries and causes high emissions of harmful substances. By generating food waste, all sources used in the production, transport or distribution of food are degraded. Wasting food also wastes water, energy, soil and money, which implies their environmental impact. The production of food that is not consumed has a significant impact on the environment. Uneaten parts of food in landfills contribute to global warming.

Food waste decomposes, producing harmful methane that escapes into the atmosphere. Rohini et al (2020), mentioned food wastage impacts biodiversity loss at a global level. In order to maximize agricultural yields, farmers have increasingly invaded wild areas in search of more fertile lands which has led to the loss of biodiversity. The volume of water used in agricultural food production is immense. Therefore, if 30 percent of all the food produced goes to waste, then it means that more than 30 percent of freshwater used in the production and processing of food also goes to waste. The food produced and then later goes to waste is estimated to be equivalent to 3.3 billion tons of greenhouse gas emission, accelerating the impacts of climate change.

Research also has it that food waste is the third biggest emitter of greenhouse gases. The reason for this is the consideration for the energy wasted and the primary use of fossil fuels in food production including processing and cooking together with transportation to various consumer markets worldwide. What's more, the methane gas produced at landfills by food thrown out as waste further aggravates climate change and global warming. In addition, according to Thomson et al. (2019) changes in dietary preferences, the distribution and quantity of food waste are likely to influence the carrying capacity, behavior, and habitat use of wildlife. 
The Resource Dispersion Hypothesis (RDH) provides an obvious theoretical basis for predicting some of the likely outcomes, at least concerning to territory size and group size. The RDH predicts that the spatial dispersion of food patches determines territory size, whereas patch richness dictates group size. Thus, where there is an abundant food source at a focal location, wildlife may congregate and focus their daily activities around this food source and have larger group sizes. The predictability of food waste as a resource can trigger population increases of opportunistic species, in turn altering predator-predator and predator-prey dynamics. For example, abundant food supplies can change the interactions between individuals, including bears tolerating other bears around rubbish dumps. In conclusion, we are aware of the impact of the fashion industry on nature, the harmfulness of mass production of products, instead of driving cars more and more bicycles, we care about animal rights and try not to produce or at least recycle waste. But few people talk about the impact of wasting food on nature (Seberini, 2019). Food waste can create a greater number of disease and malnutrition. Nowadays the food waste can be reduced through mobile apps and some other technologies. In our government to provide more facilities to reduce food waste (Rohini et al., 2020).

\section{Methodology}

The study location was at Raub, Pahang consisting of fifteen households. A purposive sampling strategy was employed to generate a sampling frame that represents a mix of characteristics. Participant characteristics are summarized in Table 1.

Prior to conducting research, a semi-structured interview was developed based on the research objectives. This study used a qualitative research approach to allow the researcher to explore deeper into the area of minimizing household's food waste. The main objective of conducting interviews with the households was to obtain first hand and up-to-date insights by garnering their experiences and knowledge on minimizing food waste.

The interviews were carried out between April and May 2021 at the researchers' office or the home of the participant. To uphold the participants' rights to confidentiality and privacy, they were briefed on the study procedure before the interview commenced. The data obtained from the participants were transcribed and analysed manually using color-coding analysis. 
Table 1

Household members demographics

\begin{tabular}{lllll}
\hline Participant & Gender & Age & Household size & Education level \\
\hline P1 & F & 25 & Family & A levels or equivalent \\
P2 & F & 48 & Family & A levels or equivalent \\
P3 & M & 49 & Single & Graduate or above \\
P4 & M & 59 & Family & Graduate or above \\
P5 & M & 56 & Family & Graduate or above \\
P6 & F & 29 & Family & A levels or equivalent \\
P7 & F & 33 & Family & Graduate or above \\
P8 & F & 54 & Family & A levels or equivalent \\
P9 & F & 33 & Single & A levels or equivalent \\
P10 & F & 30 & Family & Graduate or above \\
P11 & F & 39 & Single & Graduate or above \\
P12 & F & 50 & Family & A levels or equivalent \\
P13 & F & 35 & Family & Graduate or above \\
P14 & M & 56 & Family & A levels or equivalent \\
P15 & M & 43 & Family & A levels or equivalent
\end{tabular}

\section{Findings and Discussion}

\section{Factors Contributing to Food Waste}

A plethora of studies have been conducted to identify the causes of food waste in households, but the results obtained are varied. The participants were asked about the factors contributing to the food waste and as expected they marked more than one answer. They indicated food waste as a result of excessive shopping, preparing more food than necessary, too fussy with food choices and lifestyles.

Excessive shopping

It is believed that promotional offers such as 'buy one, get one free' motivate households to buy more than what they needed, and therefore encourage the habit of wasting food. Indeed, bulk purchases and discounted food will lead to more food waste. As Participant 2(Female; 48 years) mentioned that:

"I always easily get tempted with 'buy one, get one free'. It is cheaper compared to purchasing the item in single unit. I also looked for the discounted tag because normally those with the tag have lower prices. A lot of things we can buy at lower prices, so it motivates me to buy more and waste more food."

This statement illustrates that consumers preferred to buy their grocery at larger shopping stores that offer wide range of food brands with a lot of discounts and promotions. They noticed that large quantities or bulk purchases are available even though they are sometimes not needed. Their first intention to "only buy what I need" is becoming odds and subsequently switch shopping experiences when the stores' environment design encourages paying more than we should. The consumer felt that the shopping stores were 'laying traps' to buy more. Unlike buying the goods from the specific small markets such as butcheries, dairies, and bakeries or directly from the farmer's, we usually buy food that we only need. In some other cases, there are also consumer who are unaware about their food stocks and repeatedly purchasing items that they already have, thereby increasing possible food waste. 
Excessive buying habit is very difficult to control especially when hypermarkets utilized marketing strategies to attract consumers to increase their purchase. Most of the sales are sometimes attractive such as buy two get one free, buy two items for certain discounts, etc. It is somehow wise to purchase but to an abundance of perishable foods that are at risk of wastage such as vegetables and fruits.

Preparing more food than necessary.

Interestingly, the role of cooking practices among the influencing factors mentioned by most of the participants. Oftentimes too much food is prepared but ends up being thrown away. For example, Participant 12(Female; 50 years) stated:

"Well, I like to prepare more than needed so I do not have to worry to cook again for the dinner later. So, what I did was, I will cook extra. But sometimes my children did not take dinner and the leftover will go into the dustbin."

Preparing food at home is joyful, but it is also filled with time pressures. They show a preference for preparing a greater amount of food at once to save time. As a housewife, the concern is on the housework to be completed before tomorrow morning. Undeniable, children really appreciate the time and effort their parent takes to prepare the meal. It involves initial planning to be sure the ingredients are on hand, and it means cleaning up afterwards. However, there are sometimes children not eating the meal prepared at home. The reasons are because they had early dinner outside with friends after working or due to health-conscious. There are also sometimes children who bought outside food to be served to their parents and family members.

Research findings by Roodhuyzen et al (2017); Savelli, Francioni, \& Curina (2019) have shown that over-preparing food arises from unpredictable events changes in the household schedule such as unexpected dine out without prior notice. It may face the difficulty in effectively preventing leftover foods. The unplanned events occurring in the household indicate that food prepared is not fully consumed and end up spoiled. Hence, even most families had followed proper food preservation techniques, the unintentional situation still resulting the unwanted left over to the trash bin.

\section{Too fussy with food choices}

Several participants mentioned that it is tough for big families with children to plan the meals and predict what to cook especially in handling the picky eaters. It is believed that households with children generate more waste from meals, given the unpredictable of children's eating habits and preferences. According to Participant 8 (Female, 54 years):

"I have five kids at home, and it is so hard for me to plan their meals. They have their preferences and eating patterns. Sometimes I cook what they want to eat, to fulfil their preferences. The ugly truth is that I ended up producing more waste from those meals."

Parents found it is hard to fulfil and balance each one of their children mealtime behaviour. Therefore, parents should be creative to attract their kids to consume the food prepared at home. Colourful ingredients can be used to make the dishes delicious and tasty. Occasionally 
they could change the way they feed their children, but for the most part of food wasting was an expectation on feeding children.

\section{Lifestyle choices}

Overprovisioning of food is also linked to the perceived availability of time and was mentioned as a vital subject for most of the participants. Storing food for unexpected events is seen to reduce stress and save time among the households but could lead to buying more products than one can consume before they reach the expiry date. Participant 13 (Female; 35 years) claimed that:

"Well, sometimes I feel like I want to save my time, so I just buy from the restaurant instead of cooking and using all the ingredients that had already been bought. Also, I prefer to stockpile food for unexpected occasions, but it happened that I have no time to plan for the meals most of the time. Having an inconsistent job like mine left me no time to plan for meals."

Concerning socio-demographic characteristics, people from working class who are either working for companies or self-employed may increase the likelihood of wasting more food. This could be due to the or focus to acquire awareness on food waste (Qi and Roe, 2016). Studies into eating outside the home seek explanations for the growth of this phenomenon in recent decades and the factors which have determined that growth. Despite the heterogeneity of these studies in general terms, they could be said to approach the subject from four different perspectives. The first perspective studies the relationship between the increase in spending outside the home detected at the end of the nineteen eighties and changes in the family.

\section{Views on Food Waste}

Many insights were gathered from the participants in the subject of wasting food. The interviews with the participants provided several interesting reactions that betray their low level of awareness and possible reactions to such circumstances.

Guilt toward food waste

Despite the financial and social conditions, participants demonstrated a strong feeling of guilt towards wasting food. Among the codes that were drawn out by the participants to describe their guilt of wasting food are "food shortages and hungry children", "religion", and "throwing food culture". Participant 13 (Female; 35 years) explained that her bad habit of wasting food reminded her of hungry children in India and Africa as well as other poor families facing food shortages all around the countries. She explained that:

"Whenever I am wasting my food, I feel bad remembering all the poor kids in India and Africa struggling for food. When I watched a television program called Bersamamu, I often saw a case of poor families starving without food and really feel bad about this."

In a similar vein, for Participant 14 (Male;56 years), religion was the major factor for him not to wasting food as he argued:

"My religion prohibits me from wasting food, so I always try my best in many ways to preserve food so they do not end up in the waste bin." 
Older generation plays an important role in shaping participants' awareness toward food waste. According to Participant 15 (Male; 43 years):

"My late grandparents always told me about their stories in the old days of how they went hungry without food for several times. There was one moment where my grandmother kept herself starve due to lack of food. I feel bad when thinking about this and try to keep in my mind not to just simply waste food."

Most consumers believed that food needs to be discarded due to the expiry date on the package, when they are contaminated, having change in the texture, smell and colour, and when the food is no longer fresh. Qi and Roe (2016) reported that a household who mentioned a feeling of guilt when throwing food is more likely to eat all, which generate less food waste behaviour. They bothered on the negative behaviour and thereby try to suppress their sense of guilt by minimizing their influence.

\section{Financial concerns}

Generally, personal concerns, such as saving money, elicit a stronger motivation to reduce food waste. Financial concerns associated with the money that is lost when throwing away food are commonly mentioned as the main motivation for minimizing food waste. The need to save money especially during the pandemic was among the main reason that keeps the participants from wasting food. Few participants felt like throwing food away is similar to throwing money and associated that bad habits as monetary loss. As Participant 7 (Female; 33 years) stated:

"Frankly said, when I waste food, I feel like I am throwing my money down the drain. I think that is the simplest ways to save money during the pandemic. "

In addition, Participant 12(Female; 50 years) expressed the views that unemployment factor during pandemic caused the families to be careful on their shopping and eating habits.

"We are not from a wealthy family. My husband does not make enough money for our livings. I always advice and make sure my children not to waste any food. By looking at our conditions right now, of course we are very careful with our shopping and eating habits. Why do we need to buy things that we don't need?"

Some participants demonstrated strong emotions when they were queried about their act of wasting food. According to Participant 13 (Female; 35 years):

"Life nowadays is getting tougher. People are struggling to earn money. Everything in the supermarkets is getting more expensive. You see, with RM 50 you cannot buy much. I easily get irritated and mad if I noticed my husband or my children throw their food."

Families with less purchasing power would be expected to be more careful about how they spend their money on food. For many consumers with tight budget, children's preferences and economic loss are conceptual opposites because when children like a specific food, they will consume it and therefore not generate waste. Even when they want their children to eat 
variety of healthier foods and recognize that children may accept them after repeated exposure.

\section{Lack of environmental awareness}

Another point raised by the participants includes their lack of awareness of the environmental impact of food waste. Disappointing fact was that some of the participants believed that food waste do not harm the ecosystem but only fill the room of the landfill. For example, Participant 2 (Female; 48 years) noted that:

"As I know, wasted food will get rot in the landfill and besides, it can be chemically degraded. So, there will be no issue. There will be no harm to our environment, just that it took some space in our landfill."

Despite their relative ignorance on the environmental impact, three participants revealed their concerns on how food waste is damaging the ecosystem as illustrated by Participant 5 (Male; 56 years):

"Not many of us know that food waste is responsible for greenhouse gas emissions. I am lucky I learned during my master's degree."

By the same token, Participant 11 (Female; 39 years) claimed that there is lack of awareness among households and the benefits of food waste recycling and decomposing. According to her:

"Trust me, the majority of us did not realize the amount of food we already waste and the consequences it may bring to our ecosystem. I am personally aware of the issues and the benefits of decomposing and recycling the food waste. In fact, I have compost bin at home. That is my small initiative to save our planet."

The above statement is contrast to a study done by Jarjusey \& Chamhuri (2017), which that found a high percentage of people are still unaware of how much food they discard off even though they claim not to throw food unless it is spoilt. It shows that they do not understand the idea of reusing leftovers. Consumers are not conscious of the government efforts to curb the issues. The householders' awareness about what goes on around them about food waste is not their main concern. This is because a person with no environmental consciousness does not understand that food wastage at home impacts the life of the people in the future.

The above interviews findings demonstrate that the level of awareness and understanding of the impact of food waste on the environment among the households in Raub, Pahang, Malaysia is still low. Actions needs to be taken to raise their awareness on this matter.

\section{Implications}

The main practical implications of this study are that the results can be used to develop campaigns targeted at decreasing the amount of food waste generated at the household level. Most of the respondents believe that food waste management can reduce their cost of food expenditure as well as good for reducing environmental harm. Hence, the government should organize more campaigns to influence society at all levels to participate in sustainable food waste management activities. Since respondents have a strong perceived behavioural control to practice sustainable food waste management, the local authorities should provide more food waste management information and facilities to encourage households to engage 
in this sustainable food waste management campaign. There are many possible ways to doing these, but the best way as suggested by respondents themselves during the survey is to have the implications of food waste taught in schools starting from the kindergarten. On the other hand, the different income levels, educational backgrounds, and different occupations will need different strategies towards practicing sustainable food waste management. Hence, policymakers must plan strategies based on these strata groups.

\section{Conclusion}

In this study, the findings demonstrate that level of awareness and understanding of the impact of food waste on the environment among the households in Raub, Pahang, Malaysia is still low. These findings are in line with previous researches (Amicarelli et al., 2021). Secondly, people seem to be aware of the economic impacts of food waste but a little less unaware of the environmental ones. Economically, according to Lyndhurst (2007), many of the consumers in his study state that the cost of dumped food makes them think twice while the remaining $10 \%$ confess that they do not think about the cost at all. To curb the growing issues of food waste, local authorities initiated various strategies and campaigns to create awareness as well as ensuring practices to reduce local food waste, such as waste segregation laws, building anaerobic digesters for food courts, composting facilities, the MYSaveFood initiative, and others. However, the efforts and the efficiency of the local authority to minimize local food waste are still under observation. Perhaps, all levels of the community should increase their cooperation towards a zero-food waste culture in Malaysia. To instil this culture, further initiatives involving more people from the society should be increased since everyone holds the responsibility to reduce waste.

\section{References}

Amicarelli, V., Tricase, C., Spada, A., \& Bux, C. (2021). Households' Food Waste Behavior at Local Scale: A Cluster Analysis after the Covid-19 Lockdown. Sustainability, 13(6), 3283.

Abeliotis, K., Lasaridi, K., \& Chroni, C. (2016). Food waste prevention in Athens, Greece: The effect of family characteristics. Waste Management \& Research, 34(12), 1210-1216.

Amirudin, N., \& Gim, T. H. T. (2019). Impact of perceived food accessibility on household food waste behaviors: A case of the Klang Valley, Malaysia. Resources, Conservation and Recycling, 151, 104335.

Aschemann-Witzel, J., Giménez, A., \& Ares, G. (2018). Convenience or price orientation? Consumer characteristics influencing food waste behaviour in the context of an emerging country and the impact on future sustainability of the global food sector. Global Environmental Change, 49, 85-94.

Barr, S. (2007). Factors influencing environmental attitudes and behaviors: A UK case study of household waste management. Environment and behavior, 39(4), 435-473.

Bravi, L., Murmura, F., Savelli, E., \& Viganò, E. (2019). Motivations and actions to prevent food waste among young Italian consumers. Sustainability, 11(4), 1110.

Charbel, L., Capone, R., Grizi, L., Debs, P., Khalife, D., El Bilali, H., \& Bottalico, F. (2016). Preliminary insights on household food wastage in Lebanon. Journal of Food Security, 4(6), 131-137.

Cox, J., Giorgi, S., Sharp, V., Strange, K., Wilson, D. C., \& Blakey, N. (2010). Household waste prevention-a review of evidence. Waste Management \& Research, 28(3), 193-219.

Di Talia, E., Simeone, M., \& Scarpato, D. (2019). Consumer behaviour types in household food waste. Journal of Cleaner Production, 214, 166-172. 
Diaz-Ruiz, R., Costa-Font, M., \& Gil, J. M. (2018). Moving ahead from food-related behaviours: An alternative approach to understand household food waste generation. Journal of Cleaner Production, 172, 1140-1151.

Dobernig, K., \& Schanes, K. (2019). Domestic spaces and beyond: Consumer food waste in the context of shopping and storing routines. International Journal of Consumer Studies, 43(5), 480-489.

Elimelech, E., Ayalon, O., \& Ert, E. (2018). What gets measured gets managed: A new method of measuring household food waste. Waste Management, 76, 68-81.

Exodus Market Research. (2007). We don't waste food: A household survey. Retrieved from https://goo.gl/IXNX9Y.

Farr-Wharton, G., Foth, M., \& Choi, J. H. J. (2014). Identifying factors that promote consumer behaviours causing expired domestic food waste. Journal of Consumer Behaviour, 13(6), 393-402.

Graham-Rowe, E., Jessop, D. C., \& Sparks, P. (2014). Identifying motivations and barriers to minimising household food waste. Resources, conservation and recycling, 84, 15-23.

Griffin, M., Sobal, J., \& Lyson, T. A. (2009). An analysis of a community food waste stream. Agriculture and Human Values, 26(1), 67-81.

Gustavsson, J., Cederberg, C., Sonesson, U., Van Otterdijk, R., \& Meybeck, A. (2011). Global food losses and food waste.

Hall, K. D., Guo, J., Dore, M., \& Chow, C. C. (2009). The progressive increase of food waste in America and its environmental impact. PloS one, 4(11), e7940.

Hamilton, C., Denniss, R., \& Baker, D. (2005). Wasteful consumption in Australia (Discussion Paper No. 77). The Australia Institute, Canberra, Australia.

Hebrok, M., \& Boks, C. (2017). Household food waste: Drivers and potential intervention points for design-An extensive review. Journal of Cleaner Production, 151, 380-392.

Ilyuk, V. (2018). Like throwing a piece of me away: How online and in-store grocery purchase channels affect consumers' food waste. Journal of Retailing and Consumer Services, 41, 20-30.

Ismail, M. H., Ghazi, T. I. M., Hamzah, M. H., Abd Manaf, L., Tahir, R. M., Nasir, A. M., \& Omar, A. E. (2020). Impact of Movement Control Order (MCO) due to Coronavirus Disease (COVID-19) on Food Waste Generation: A Case Study in Klang Valley, Malaysia. Sustainability, 12(21), 1-17.

Ismail, M. H., Ghazi, T. I. M., Hamzah, M. H., Abd Manaf, L., Tahir, R. M., Nasir, A. M., \& Omar, A. E. (2020). Impact of Movement Control Order (MCO) due to Coronavirus Disease (COVID-19) on Food Waste Generation: A Case Study in Klang Valley, Malaysia. Sustainability, 12(21), 1-17.

Jarjusey, F. A. T. O. U. M. A. T. A., \& Chamhuri, N. O. R. S. H. A. M. L. I. Z. A. (2017). Consumers' awareness and knowledge about food waste in Selangor, Malaysia. International Journal of Business and Economic Affairs, 2(2), 91-97.

Jay, B. N. (2019). Turn left over into nutritious meals, reduce food wastage. Available online: https://www.nst.com.my/news/nation/2017/10/286917/turn-leftovers-nutritiousmealsreduce-food-wastage.

Jereme, I. A., Siwar, C., Begum, R. A., \& Talib, B. A. (2016). Addressing the problems of food waste generation in Malaysia. International Journal of Advanced and Applied Sciences, 3(8), 68-77. 
Jörissen, J., Priefer, C., \& Bräutigam, K. R. (2015). Food waste generation at household level: Results of a survey among employees of two European research centers in Italy and Germany. Sustainability, 7(3), 2695-2715.

Jribi, S., Ismail, H. B., Doggui, D., \& Debbabi, H. (2020). COVID-19 virus outbreak lockdown: What impacts on household food wastage? Environment, Development and Sustainability, 22(5), 3939-3955.

Kasavan, S., Mohamed, A. F., \& Halim, S. A. (2018). Knowledge and Attitudes of Hoteliers in Langkawi UNESCO Global Geopark towards Sustainable Food Waste Management (SFWM). Pertanika Journal of Social Sciences \& Humanities, 26(3).

Kasavan, S., Mohamed, A. F., \& Halim, S. A. (2019). Drivers of food waste generation: Case study of island-based hotels in Langkawi, Malaysia. Waste management, 91, 72-79.

Kibler, K. M., Reinhart, D., Hawkins, C., Motlagh, A. M., \& Wright, J. (2018). Food waste and the food-energy-water nexus: a review of food waste management alternatives. Waste management, 74, 52-62.

Kraus, K., \& Emontspool, J. (2017). Guilt and Loathing in the Kitchen: Why Sustainable Consumers Waste Food. ACR North American Advances.

Lee, K. C. (2018). Grocery shopping, food waste, and the retail landscape of cities: The case of Seoul. Journal of Cleaner Production, 172, 325-334.

Lim, W. J., Chin, N. L., Yusof, A. Y., Yahya, A., \& Tee, T. P. (2016). Food waste handling in Malaysia and comparison with other Asian countries. International Food Research Journal, 23, S1.

Loke, M. K., \& Leung, P. (2015). Quantifying food waste in Hawaii's food supply chain. Waste Management \& Research, 33(12), 1076-1083.

Lyndhurst, B. (2007). Food behaviour consumer research-findings from the quantitative survey. Banbury, UK: WRAP.

Lyndhurst, B., Cox, J., \& Downing, P. (2007). Food behaviour consumer research: Quantitative phase. Waste \& Resources Action Programme (WRAP): Banbury, UK.

Mohamed, A. F., Idrus, S., \& Hadi, A. S. (2017). Challenges of Urban Space for Sustainable Solid Waste Management in the Langat Basin, Malaysia. International Journal of the Malay World and Civilisation (Iman).

Østergaard, S., \& Hanssen, O. J. (2018). Wasting of fresh-packed bread by consumersinfluence of shopping behavior, storing, handling, and consumer

preferences. Sustainability, 10(7), 2251.

Papargyropoulou, E., Padfield, R., Rupani, P. F., \& Zakaria, Z. (2014). Towards sustainable resource and waste management in developing countries: The role of commercial and food waste in Malaysia. International Journal of Waste Resources, 4(3), 2-7.

Papargyropoulou, E., Wright, N., Lozano, R., Steinberger, J., Padfield, R., \& Ujang, Z. (2016). Conceptual framework for the study of food waste generation and prevention in the hospitality sector. Waste management, 49, 326-336.

Paritosh, K., Kushwaha, S. K., Yadav, M., Pareek, N., Chawade, A., \& Vivekanand, V. (2017). Food waste to energy: an overview of sustainable approaches for food waste management and nutrient recycling. BioMed Research International, 2017.

Parizeau, K., Von Massow, M., \& Martin, R. (2015). Household-level dynamics of food waste production and related beliefs, attitudes, and behaviours in Guelph, Ontario. Waste management, 35, 207-217. 
Ponis, S. T., Papanikolaou, P. A., Katimertzoglou, P., Ntalla, A. C., \& Xenos, K. I. (2017). Household food waste in Greece: A questionnaire survey.Journal of Cleaner Production, 149, 1268-1277.

Porpino, G., Parente, J., \& Wansink, B. (2015). Food waste paradox: antecedents of food disposal in low-income households. International journal of consumer studies, 39(6), 619-629.

Priefer, C., Jörissen, J., \& Bräutigam, K. R. (2016). Food waste prevention in Europe-A causedriven approach to identify the most relevant leverage points for action. Resources, Conservation and Recycling, 109, 155-165.

Qi, D., Roe, B. E. (2016). Household food waste: multivariate regression and principal components analyses of awareness and attitudes among U.S. Consumers. PLoS One 11 (7) e0159250. https://doi.org/10.1371/journal.pone.0159250

Rohini, C., Geetha, P. S., Vijayalakshmi, R., Mini, M. L., \& Pasupathi, E. (2020). Global effects of food waste. Journal of Pharmacognosy and Phytochemistry, 9(2), 690-699.

Roodhuyzen, D. M., Luning, P. A., Fogliano, V., \& Steenbekkers, L. P. A. (2017). Putting together the puzzle of consumer food waste: Towards an integral perspective. Trends in Food Science \& Technology, 68, 37-50.

Samdin, Z., Bakori, K. A., \& Hassan, H. (2012). Factors influencing environmental management practices among hotels in Malaysia. International Journal of Humanities and Social Sciences, 6(5), 889-892.

Savelli, E., Francioni, B., \& Curina, I. (2019). Healthy lifestyle and food waste behavior. Journal of Consumer Marketing.

Schanes, K., Dobernig, K., \& Gözet, B. (2018). Food waste matters-A systematic review of household food waste practices and their policy implications. Journal of Cleaner Production, 182, 978-991.

Seberini, A. (2020). Economic, social and environmental world impacts of food waste on society and Zero waste as a global approach to their elimination. In SHS Web of Conferences (Vol. 74, p. 03010). EDP Sciences.

Solid Waste Management Report (2015). Available online. http://www.kpkt.gov.my/resources/index/user_1/Attachments/hebahan_slider/slaid_ dapat an_makmal.pdf (accessed on January 5, 2019)

Stancu, V., Haugaard, P., \& Lähteenmäki, L. (2016). Determinants of consumer food waste behaviour: Two routes to food waste. Appetite, 96, 7-17.

Stefan, V., van Herpen, E., Tudoran, A. A., \& Lähteenmäki, L. (2013). Avoiding food waste by Romanian consumers: The importance of planning and shopping routines. Food Quality and Preference, 28(1), 375-381.

Sundaram, J. K., Gen, T. Z., \& Jarud, R. K. (2019). Achieving food security for all Malaysians. Khazanah Research Institute: Kuala Lumpur, Malaysia, 1-78. SWCorp (2015). SWCorp. Retrieved from www.swcorp.gov.my.

Thompson, L. A., \& Darwish, W. S. (2019). Environmental chemical contaminants in food: review of a global problem. Journal of toxicology, 2019.

Thyberg, K. L., \& Tonjes, D. J. (2016). Drivers of food waste and their implications for sustainable policy development. Resources, Conservation and Recycling, 106, 110-123.

United States Department of Agriculture (2019). The Impact of Food Waste; United States Department of Agriculture: Washington, DC, USA. 
Visschers, V. H., Wickli, N., \& Siegrist, M. (2016). Sorting out food waste behaviour: A survey on the motivators and barriers of self-reported amounts of food waste in households. Journal of Environmental Psychology, 45, 66-78.

Williams, H., Wikström, F., Otterbring, T., Löfgren, M., \& Gustafsson, A. (2012). Reasons for household food waste with special attention to packaging. Journal of cleaner production, 24, 141-148.

Yusof, N. S. H. C., Yap, B. W., Maad, H. A., \& Hussin, W. N. I. W. (2016). Relationship between emotional intelligence and university students' attitude. Journal of Social Sciences \& Humanities, 24, 119-130.

Zainal, D., \& Hassan, K. A. (2019). Factors Influencing household food waste behaviour in Malaysia. Int. J. Res. Bus. Econ. Manag, 3, 56-71. 